\section{Spontaneous recanalization of the basilar artery with conservative management months after symptom onset}

\author{
Joel M. Oster and Puja Aggarwal \\ Department of Neurology, Lahey Clinic, \\ Burlington, MA, USA
}

\begin{abstract}
Basilar artery occlusion may be associated with a poor prognosis in the absence of recanalization. Choices in aggressive treatment for this potentially fatal condition vary from intra-arterial or intravenous thrombolysis, endovascular removal, or a combination of the two, with adjunct anti-coagulation therapy. These therapies have proven to be effective in recanalization, whereas conservative management with anti-coagulants alone has had more limited success in the literature. We report a case of basilar artery occlusion managed conservatively with unfractionated heparin, resulting in complete recanalization 3.5 months after symptom onset. Conservative management of basilar artery occlusion with unfractionated heparin was associated with complete recanalization long after symptom onset.
\end{abstract}

\section{Introduction}

Basilar artery occlusion (BA0) has been associated with a high morbidity and mortality, compromising posterior cerebral blood flow to the occipital lobes, medial temporal lobes, the thalami, the cerebellum, and the brain stem. ${ }^{1}$ Occlusion in the basilar artery is most often due to atherosclerotic changes or cardioemboli. ${ }^{2,3}$ Clinical recovery is virtually impossible in the absence of recanalization. ${ }^{3,4}$ A medical emergency, BA0 calls for aggressive therapies to address clot dissolution, via intraarterial thrombolysis (IAT), intravenous thrombolysis (IVT), and/or endovascular removal. Adjunct therapies include continued heparin and anti-platelet therapies. We report a case in which recanalization on MRA occurs in the absence of aggressive therapy.

\section{Case Report}

A 58-year old patient with global left ventricular hypokinesis and wall motion abnormalities presented with acute ataxia, hemiparesis, and decreasing alertness. Initial MRI revealed critically decreased basilar arterial flow likely secondary to a tight stenosis versus complete occlusion of the vessel (Figure 1), and multiple associated strokes in the posterior circulation distribution (Figure 2). Intervention with intra-arterial clot lysis and thrombolytic therapy were initially considered but the patient and family declined an interventional approach, thrombolytic therapy, or angiography. The patient was subsequently admitted to the ICU, kept flat under close observation for several days, received unfractionated IV heparin, and subsequently was administered warfarin over multiple days. Once his course was stable he was discharged to a rehabilitation hospital. The patient had a follow-up MRI/MRA approximately 3.5 months later illustrating no new strokes and complete recanalization of the basilar artery (Figure 3 ). He remains on warfarin, is ambulatory, lives independently, and has only a mild residual hemiparesis and ataxia.
Correspondence: Joel M. Oster, Department of Neurology, Lahey Clinic, 41 Mall Rd, Burlington, MA 01803, USA. E-mail: joel.m.oster@lahey.org

Key words: basilar artery occlusion, conservative management, spontaneous recanalization.

Received for publication: 13 October 2009. Accepted for publication: 19 0ctober 2009.

This work is licensed under a Creative Commons Attribution 3.0 License (by-nc 3.0).

(C) Copyright J.M. Oster and P. Aggarwal, 2009 Licensee PAGEPress, Italy

Neurology International 2009; 1:e17 doi:10.4081/ni.2009.e17

\section{Discussion}

BAO can have morbid outcomes, and mortality rate has been reportedly $85-98 \%$ even with fibrinolytic, and/or endovascular therapy, if not recanalized. ${ }^{2,47}$ Morbidities with thrombolysis

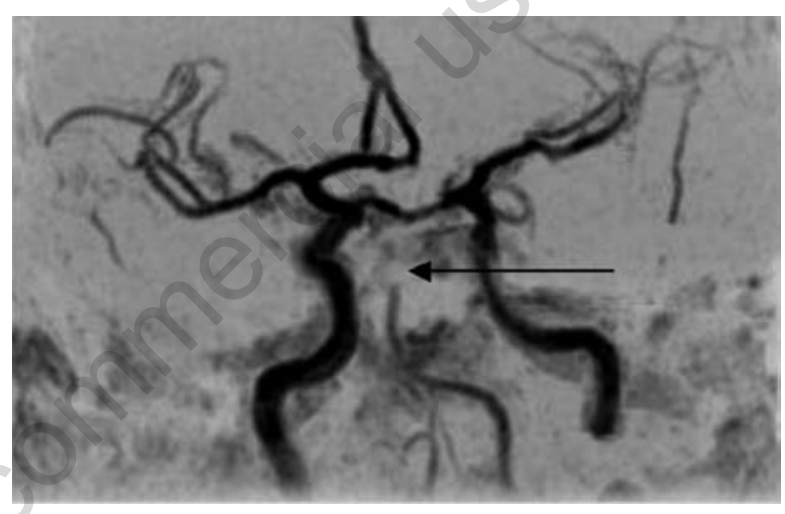

Figure 1. Magnetic resonance angiography at onset of symptoms revealed basilar stenosis persistent with basilar artery occlusion (arrow).
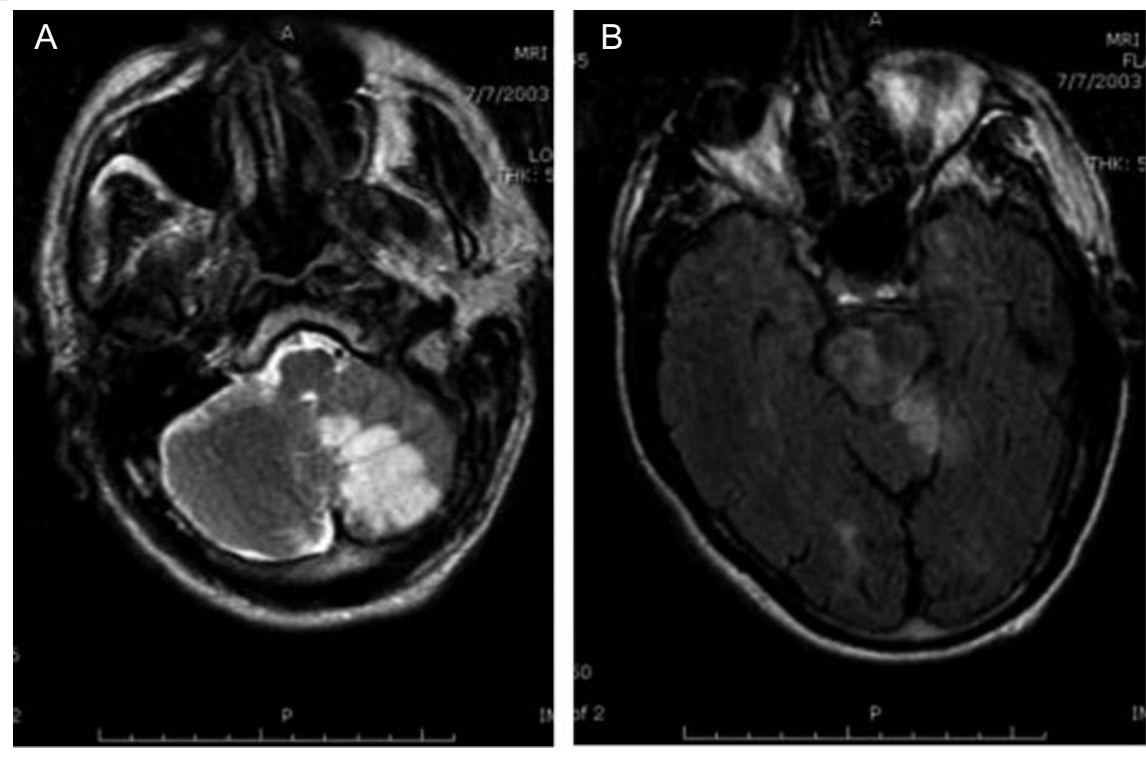

Figure 2. At the time of presentation, T2 weighted imaging showed infarcts in the cerebellum (A) and axial FLAIR imaging showed infarcts in the brainstem (B). 


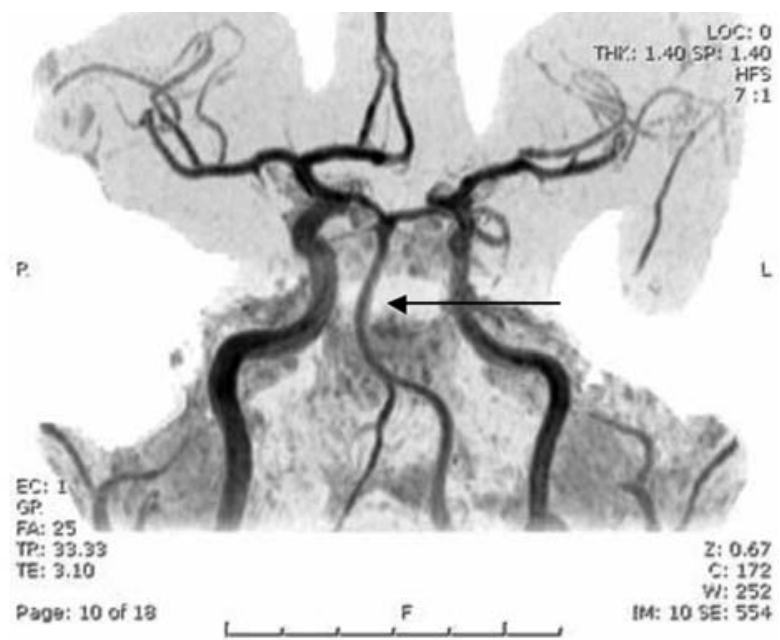

include extracerebral hemorrhage, asymptomatic or symptomatic acute intracerebral hemorrhage, and neurological damage, most concerning of which is the "locked-in" state ${ }^{7-11}$ may occur if these therapies are not considered and bilateral infarction of the brainstem occurs. The outcome of acute BAO depends on the length and location of occlusion, degree of recanalization, and time between onset of symptoms and treatment. ${ }^{2,5,6,12-16}$ Hospital based factors are also important, in that there are a limited number of centers with interventional neuroradiologists capable of endovascular therapy. ${ }^{17}$ Various studies have been carried out comparing the efficacy of IAT versus IVT therapy, and/or endovascular management in the setting of BAO, all resulting in remarkable rates of recanalization. The aggressive treatment options are associated with a significant improvement in occlusion; IVT or IAT results in about $40-65 \%$ recanalization with $22-24 \%$ favorable outcome. ${ }^{1,2,5,6,10,14}$ The lower improvement in morbidity and the serious risks of these therapies may be grounds for further investigation into conservative management via anti-coagulants potentially resulting in spontaneous recanalization. Our patient's decision to elect medical therapy may be supported by the data of the BASICS study which failed to show any special benefit to IA therapy over IV therapies, with more aggressive therapies entailing greater risks. ${ }^{18}$

Early spontaneous recanalization has been reported in the anterior cerebral circulation, whereas late spontaneous recanalization has been documented only in the extracerebral circulation. ${ }^{19,20}$ The MR angiography changes in our patient illustrate that the use of conservative treatment with unfractionated heparin in an acute setting of basilar thrombosis was associated with complete recanalization and restoration of blood flow on MRA by an unknown mechanism within 3.5 months, with a good clinical outcome. There are limited, if any, documented reports of late spontaneous recanalization of the posterior cerebral circu-
Figure 3. Repeat magnetic resonance angiography 3.5 months after symptom onset revealed a complete recanalization of the previously occluded basilar artery on MRA (arrow).

lation similar to our case in the English language literature. The incidence, mechanism, and ideal management of this extraordinary finding remain unclear. Reports of this nature call for further investigation into the underlying mechanism of spontaneous recanalization.

\section{References}

1. Yu W, Kostanian V, Fisher M. Endovascular recanalization of basilar artery occlusion 80 days after symptom onset. Stroke 2007;38:1387-9.

2. Lindsberg PJ, Mattle HP. Therapy of basilar artery occlusion: a systematic analysis comparing intra-arterial and intravenous thrombolysis. Stroke 2006;37:922-8.

3. Weimar C, Goertler M, Harms L, Diener HC. Distribution and outcome of symptomatic stenoses and occlusions in patients with acute cerebral ischemia. Arch Neurol 2006;63:1287-91.

4. Baird TA, Muir KW, Bone I. Basilar artery occlusion. Neurocritical Care 2004;3:31930 .

5. Brandt T, von Kummer R, Muller-Kuppers M, Hacke W. Thrombolytic therapy of acute basilar artery occlusion: variables affecting recanalization and outcome. Stroke 1996;27:875-81.

6. Hacke W, Zeumer H, Ferbert A, et al. Intraarterial thrombolytic therapy improves outcome in patients with acute vertebrobasilar occlusive disease. Stroke 1988; 19:1216-22.

7. Lindsberg PJ, Soinne L, Roine R0, Tatlisumak T. Options for recanalization therapy in basilar artery occlusion. Stroke 2005;36:203-4.

8. Chapot R, Houdart E, Rogopoulos A, et al. Thromboaspiration in the basilar artery: report of two cases. AJNR Am J Neuroradiol 2002;23:282-4.
9. Wijdicks E, Nichols DA, Thielen KR, et al. Intra-arterial thrombolysis in acute basilar artery thromboembolism: the initial Mayo Clinic experience. Mayo Clin Proc 1997;72: 1005-13.

10. Lindsberg PJ, Soinne L, Tatlisumak T, et al. Long-term outcome after intravenous thrombolysis of basilar artery occlusion. JAMA 2004;292:1862-6.

11. Smith E, Delargy M. Locked-In syndrome. Br Med J 2005;330:406-9.

12. Archer CR, Horenstein S. Basilar artery occlusion: clinical and radiological correlation. Stroke 1977;8:383-90.

13. Eckert B, Koch C, Thomalla G, et al. Aggressive therapy with intravenous abciximab and intra-arterial rtPA and additional PTA/stenting improves clinical outcome in acute vertebrobasilar occlusion. Combined local fibrinolysis and intravenous abciximab in acute vertebrobasilar stroke treatment (FAST). Results of a multicenter study. Stroke 2005;36:1160-5.

14. Cross DT, Derdeyn CP, Moran CJ. Bleeding complications after basilar artery fibrinolysis with tissue plasminogen activator. AJNR Am J Neuroradiol 2001;22:521-5.

15. Levy EI, Firlik AD, Wisniewski S, et al. Factors affecting survival rates for acute vertebrobasilar artery occlusions treated with intraarterial thrombolytic therapy: a meta-analytical approach. Neurosurgery 1999;45:539-45.

16. Macleod MR, Davis SM, Mitchell PJ, et al. Results of a multicentre, randomised controlled trial of intra-arterial urokinase in the treatment of acute posterior circulation ischaemic stroke. Cerebrovasc Dis 2005;20:12-7.

17. Pfefferkorn T, Mayer TE, Opherk C, et al. Staged escalation therapy in acute basilar artery occlusion. Intravenous thrombolysis and on-demand consecutive endovascular mechanical thrombectomy: preliminary experience in 16 patients. Stroke. 2008;39:1496-500.

18. Schonewille WJ, Wijman CA, Michel P et al. Treatment and outcomes of acute basilar artery occlusion in the Basilar Artery International Cooperation Study (BASICS): a prospective registry study. Lancet Neurol 2009;8:724-30.

19. Kassem-Moussa H, Graffagnino C. Nonocclusion and spontaneous recanalization rates in acute ischemic stroke: a review of cerebral angiography studies. Arch Neurol 2002;59:1870-3.

20. Klonaris C, Alexandrou A, Katsargyris A, Liasis N, Bastounis E. Late spontaneous recanalization of acute internal carotid artery occlusion. J Vasc Surg 2006;43:8447. 